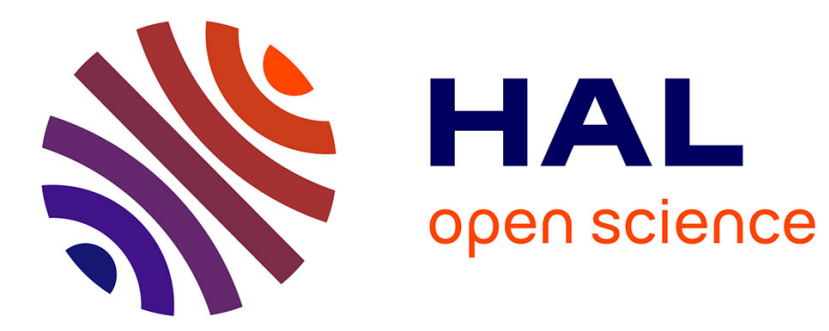

\title{
The value of lies in an ultimatum game with imperfect information
}

Damien Besancenot, Delphine Dubart, Radu Vranceanu

\section{To cite this version:}

Damien Besancenot, Delphine Dubart, Radu Vranceanu. The value of lies in an ultimatum game with imperfect information. 2012. hal-00692139

\section{HAL Id: hal-00692139 \\ https://essec.hal.science/hal-00692139}

Preprint submitted on 28 Apr 2012

HAL is a multi-disciplinary open access archive for the deposit and dissemination of scientific research documents, whether they are published or not. The documents may come from teaching and research institutions in France or abroad, or from public or private research centers.
L'archive ouverte pluridisciplinaire HAL, est destinée au dépôt et à la diffusion de documents scientifiques de niveau recherche, publiés ou non, émanant des établissements d'enseignement et de recherche français ou étrangers, des laboratoires publics ou privés. 


\title{
The value of lies in an ultimatum game with imperfect information
}

\author{
Research Center \\ ESSEC Working Paper 1207
}

2012

Damien Besancenot

Delphine Dubart

Radu Vranceanu 
April 16, 2012

\title{
THE VALUE OF LIES IN AN ULTIMATUM GAME WITH IMPERFECT INFORMATION
}

\author{
Damien Besancenot, Delphine Dubart ${ }^{\dagger}$ and Radu Vranceanu ${ }^{\ddagger}$ \\ ESSEC Business School Working Paper \#1207
}

\begin{abstract}
Humans often lie strategically. We study this problem in an ultimatum game involving informed proposers and uninformed responders, where the former can send an unverifiable statement about their endowment. If there are some intrinsically honest proposers, a simple message game shows that the rest of them are likely to declare a lower-than-actual endowment to the responders. In the second part of the paper, we report on an experiment testing this game. On average, $88.5 \%$ of the proposers understate the actual endowment by $20.5 \%$. Regression analysis shows that a one-dollar gap between the actual and declared amounts prompts proposers to reduce their offer by 19 cents. However, responders appear not to take such claims seriously, and thus the frequency of rejections should increase. The consequence is a net welfare loss, that is specific to such a "free-to-lie" environment.

Keywords: Ultimatum game, Asymmetric information, Lying costs, Strategic lies, Deception, Welfare loss.

JEL Classification: C91; D82; D83.
\end{abstract}

\footnotetext{
${ }^{*}$ University of Paris 13 and CEPN, 99 rue Jean-Baptiste Clément, 93430, Villetaneuse, France. E-mail: besancenot.damien@univ-paris13.fr

${ }^{\dagger}$ ESSEC Business School, ESSEC Behavioral Lab. PB 50105, 95021 Cergy, France. E-mail: dubart@essec.fr

${ }^{\ddagger}$ Corresponding author. ESSEC Business School and THEMA. PB 50105, 95021 Cergy, France. E-mail: vranceanu@essec.fr
} 


\section{Introduction}

Humans sometimes resort to lies as a tool for leveraging on negotiation power (e.g., Lewicki, 1983; Anton, 1990; Shapiro and Bies, 1994). As noted by Lewicki and Stark (1996, p.77), in a negotiation context, "lies misinform the opponent, eliminate or obscure the opponent choice alternatives, or manipulate the perceived costs and benefits of particular choice options open to the opponent". Clearly, in a world entirely populated by liars, messages would not be taken seriously by their recipients. ${ }^{1}$ The ability of these less ethical people to manipulate the beliefs of others is therefore grounded in the existence of at least some individuals who have a significant aversion to lying (Kartik et al., 2007; Chen et al., 2008; Kartik, 2009).

There is a growing body of experimental economics literature on lying and deception that focuses on what motivates individuals to resort to such questionable communication methods. In this context, players are generally referred to as the Sender (of the message) and the Receiver. Gneezy (2005) submits an interesting typology of lies with respect to players' payoffs. If the lie, defined as a misrepresentation of reality, brings about an improvement in both players' well-being, we have a "Pareto white lie"; if the sender is worse-off but the receiver is better-off, we have "an altruistic white lie". If the sender is better-off while the receiver is worse-off, this is the typical "selfish lie", which Gneezy (2005) acknowledges to be the most relevant category for many economic events. Taking stock from a two-person interaction experiment, he shows that a non-negligible number of subjects lie in order to reap some benefit, even if this involves a loss for their partner in the game; subjects' inclination to lie increases the more they have to gain from the lie, and decreases the more the others will lose from it.

\footnotetext{
${ }^{1}$ Pioneering studies in the analysis of strategic information manipulation were submitted by Crawford and Sobel (1982) and Sobel (1985). In these papers agents can send misleading messages without a direct cost, i.e. they can undertake "cheap talk". In equilibrium, the messages do no alter the action of the receiver.
} 
One important finding of these empirical studies is that humans inherently present some form of aversion to lying, although its extent can vary greatly from one individual to another. Lundquist et al. (2009) find that aversion to lying increases with the size of the lie. Erat and Gneezy (2011) show that a majority of people are reluctant to tell even Pareto white lies, which suggests that lie aversion is independent of any social preference over outcomes. Hurkens and Kartick (2009) argue that some people might never lie and others would lie whenever they prefer the outcome of lying to the outcome of telling the truth (irrespective of the consequences of the lie). Sánchez-Pagés (2006) analyzes a truth-telling game where senders and receivers have conflicting goals, and observes that some subjects reject material incentives to misbehave. There is an open debate on the inner nature of lying costs, some scholars claiming that people have an inner aversion to telling lies (Vanberg 2008), and others suggesting that people refrain from lying because they do not like to deceive others (Charness and Dufwenberg, 2006; 2010). Hao and Houser (2010) provide experimental evidence to support the hypothesis that the only reason many people refrain from lying is to preserve their image of an honest person, but they willingly turn to lying when their action is hidden. However, in their experiment too, about $44 \%$ of the subjects exhibit an intrinsic preference for honesty even under secrecy.

In this paper, we aim to study the inner mechanism of misleading communication in the negotiation context specific to the ultimatum game (Güth et al. 1982). In the standard experimental setup, the two players are often referred to as the Proposer and the Responder. The Proposer is endowed with an amount of money and must make an offer as how to divide this sum between them. The Responder can accept the offer, in which case the endowment is divided as proposed, or reject it, in which case both players receive nothing. The subgame perfect Nash equilibrium with pure self-interest predicts that responders should accept any 
positive amount, and, knowing this, proposers should make close-to-zero offers. This result has been invalidated by an impressive number of tests (Roth, 1995). As documented by Oosterbeek et al. (2004) in a meta-analysis covering 37 papers, on average proposers offer about $40 \%$ of the "pie"; also, about $16 \%$ of the offers are rejected. ${ }^{2}$ These results have been interpreted as evidence of an inherent concern for fairness concern specific to human beings (Camerer, 2003).

In order to allow the proposer to send misleading messages, we make sure that the responder has only imperfect information about the proposer's endowment. ${ }^{3}$ The proposer is then asked to send a message indicating the amount of money received at the outset of the game; this is unverifiable information for the responder. The proposer's strategic advantage over the responder is thus twofold: he makes the first move and has full information about his position in the game. The responder's negotiation power stems from his ability to turn down the offer submitted by the proposer, at a cost for himself. We expect the responder to reject "unfair" offers; knowing this, the proposer should make offers that the former is likely to accept.

In the first part of the paper, we develop a simple message model in this ultimatum framework, building on the theoretical literature on strategic communication with lying costs (Kartik et al., 2007; Chen et al., 2008; Kartik, 2009). If there are some intrinsically honest proposers, we show that the others will claim that they received a smaller endowment simply to push down responders' expectations about this endowment and hence submit lower acceptable offers. The trade-off between lying costs and lying benefits is thus at the heart of the paper. In the second part of the paper, we implement an experiment where anonymous

\footnotetext{
${ }^{2}$ See Bearden (2001) for an almost exhaustive survey of the literature on this game.

${ }^{3}$ Many authors have studied ultimatum games with imperfect information, be it uncertainty or ambiguity (inter alia, Mitzkewitz and Nagel, 1993; Straub and Murnighan, 1995; Kagel et al. 1996; Güth et al., 1996; Rapoport and Sundali, 1996; Croson, 1996). A standard result is that proposers make substantially lower absolute offers as compared to the perfect information case.
} 
pairs of subjects were asked to play the game described above four times. At the outset of a given round, the computer chooses the proposer's endowment from a uniform distribution; responders know this distribution. The proposers make an offer and send their message. The empirical results corroborate the theoretical model's predictions of proposers' behavior; the proposers understate the actual amount in $88.5 \%$ of messages (by $19 \%$ on average). However, the empirical evidence on responders' behavior challenges the theoretical model. On average, they base their accept/reject decision on the offer alone ignoring the message. As a result, the frequency of rejections, bringing about losses for both parties, is higher than in a truth-telling context. Probably one important contribution of this paper is to point out that, at least in this simple interaction, the "free-to-lie environment" is socially inefficient.

Our experiment - combining an ultimatum game with imperfect information and a message game - can be seen as an extension of the empirical study by Croson et al. (2003). ${ }^{4}$ In their paper, pairs of subjects play, four times, an ultimatum game with an outside option for responders if they reject the proposers' offer, under various information treatments. In one treatment, proposers know the size of the pie (actually one of four possible values), while responders know that it can be anything between two given bounds (responders are thus subject to decision ambiguity). Croson et al. (2003) also allow for players to exchange messages and use a dummy variable to record a misleading/true message. In contrast to their study, in our experiment responders know the statistical distribution of the proposers' endowment; these amounts are drawn from an almost continuous distribution, an approach adopted by Rapoport and Sundali (1996). Proposers' lies are measured by the difference between the declared and the actual amount, not by a dummy variable. We can therefore estimate the "subjective value" of a one-dollar lie, i.e. by how much on average a proposer

\footnotetext{
${ }^{4}$ See also the companion paper (Boles, Croson and Murnighan, 2000).
} 
reduces his offer each time he understates his endowment by one dollar.

The paper is organized as follows. The next section presents a theoretical analysis of the lying strategy in an ultimatum game with imperfect information. Section 3 introduces the experiment. The last section presents the conclusion.

\section{Theory: the "message game"}

\subsection{Main assumptions}

In this section we aim at analyzing the communication strategy of a Proposer in an ultimatum game with one-side imperfect information. We consider a pair of players taken at random from a large population of individuals. Within a basic pair the two players will be referred to as the Proposer and the Responder. To keep the analysis as simple as possible, we assume that individuals are identical in everything but their aversion to lying.

At the outset of the game, the proposer gets a cash endowment $Y$ randomly chosen in the range $[0, A]$ according to an uniform distribution. The responder does not observe this endowment, but know the statistical distribution. Then the proposer must make two decisions. He must send a message $M$ to the responder about the value of $Y$ and must make a cash offer $Z$, with $Z<Y$. The message can be true $(M=Y)$ or false $(M \neq Y)$. The responder cannot verify it. At the last stage, the responder who gets the offer $Z$ and the message $M$ must decide whether to accept or to reject the offer. If he accepts the offer, the proposer gets $(Y-Z)$ and the responder gets $Z$; if he rejects the offer, both players get nothing.

Players aim to maximize their expected utility given their set of feasible strategies. In this simple model, we assume that - all things equal - players prefer more money to less, have fairness concerns, and present an aversion to lying, i.e. they dislike misrepresenting reality. 
For an individual $k$, lying aversion is represented by a cost $C_{k}$ that the individual incurs whenever he tells a lie; following Lundquist et al. (2009), we admit that this cost is proportional to the "size of the lie", i.e. the gap between the declared and the true value of the variable of interest; we can write the total cost as $C_{k}=c_{k}|Y-M|$, where $c_{k}>0$ is the marginal cost of one-dollar lie. There are two types players with respect to the lying cost. ${ }^{5}$ Following the experimental evidence brought by Hurkens and Kartick (2009), Hao and Houser (2010) or Erat and Gneezy (2011), we admit that a share $\alpha$ of the population is made of intrinsically honest individuals or "H-type players". For those players, the lying cost always exceeds the reward they can get from a false message $M$ (in other words, $c_{H}$ is large enough). All other $(1-\alpha)$ individuals have a marginal cost $c_{L}=c$, with $c$ small enough; they might consider the trade-off between bearing the cost of a lie $(M<Y)$ and the gain from making a lower offer $Z .^{6}$ We refer to these would-be liars as the "L-type players".

Fehr and Schmidt (1999) argued that individuals in a position to compare their own gain with that of a reference group incurs an utility loss if their gain is below the average income of the group, what they call "disadvantageous inequality aversion", and can also bear an utility loss if they have a gain higher than the reference group, what they call "advantageous inequality aversion". They argue that an individual's sensibility to advantageous inequality aversion should be lower than the sensibility to disadvantageous inequality aversion. For the sake of simplicity, in this paper we assume that the two players in our ultimatum game are not sensible to advantageous inequality, i.e. they do not suffer an utility loss if they earn more than the other. We also admit that all subjects present the same aversion to disadvantageous inequality.

The ultimatum game is a two-player interaction. If we use the index $k$ and $-k$ to denote

\footnotetext{
${ }^{5}$ This is the only differentiating characteristic of individuals in this model.

${ }^{6}$ The threshold $\tilde{c}$ separating a honest person from a liar is engodeneous; we will determine it latter on.
} 
the two persons, and denote their payoffs by respectively $x_{k}$ and $x_{-k}$, the utility function of individual $k$ can be written as:

$$
U_{k}\left(x_{k}\right)=x_{k}-\mathbf{1}_{\left(x_{k}<x_{-k}\right)} v\left(x_{-k}-x_{k}\right)-\mathbf{1}_{l i e} C_{k},
$$

where $\mathbf{1}_{\left(x_{k}<x_{-k}\right)}$ is a dummy variable that takes the value 1 if $x_{k}<x_{-k}$ and 0 if else, parameter $v$ (with $v>0$ ) captures the utility loss related to "disadvantageous inequality" of individual $k$ and $\mathbf{1}_{\text {lie }}$ takes the value 1 if $M \neq Y$ (lie) and 0 in the opposite case (truth). ${ }^{7}$ For any given $x_{-k}$, if $x_{k}<x_{-k}$ it turns out that $\partial U_{k}\left(x_{k}\right) / \partial x_{k}=(1+v)$; if $x_{k}>x_{-k}$ we have $\partial U_{k}\left(x_{k}\right) / \partial x_{k}=1$. In both cases, the utility is an increasing function in a player's own gain.

\section{$2.2 \quad$ Strategies}

For sure, for any player $k$, the game is acceptable if and only if $U_{k}\left(x_{k}\right) \geq 0$ :

$$
U_{k}\left(x_{k}\right) \geq 0 \Leftrightarrow x_{k} \geq \frac{v x_{-k}+\mathbf{1}_{l i e} C_{k}}{1+v}
$$

Notice that in our setup only the proposer can issue a wrong message. Since the responder is not subject to the lie/tell-the-truth choice, the participation constraint for the responder can be written as:

$$
x_{k} \geq\left(\frac{v}{1+v}\right) x_{-k}
$$

Denoting by $Y$ the total sum to be shared between the two players, with $Y=x_{k}+x_{-k}$, the responder's participation constraint can be interpreted as a fairness constraint: he will accept any offer $x_{k}$ providing him with a "fair share" of the pie:

$$
\left.x_{k} \geq \Phi Y, \text { with } \Phi=\left(\frac{v}{1+2 v}\right) \in\right] 0 ; 0.5[\text { and } d \Phi / d v>0 .
$$

Given that the responder does not know $Y$, his decision to accept or not the allocation will be based on his expected value of $Y$ contingent upon the signal $M$ issued by the proposer, denoted by $E[Y \mid M]$.

\footnotetext{
7 This linear form was introduced by Fehr and Schmidt (1999).
} 
For a given strategy $(M, Z)$ played by the proposer, the responder's optimal "pie-sharing strategy" will be:

$$
\text { Responder pie-sharing strategy }\left\{\begin{array}{ll}
\text { Accept the offer } Z \text { if: } & Z \geq \Phi E[Y \mid M] \\
\text { Refuse the offer } Z \text { if: } & Z<\Phi E[Y \mid M]
\end{array}\right. \text {. }
$$

A proposer who aims at maximizing an utility function such as defined in Eq. (1) will make the smallest offer $Z$ that the responder accepts, to get the largest gain $(Y-Z)$. The best "pie sharing" strategy for the proposer is thus to offer the lowest acceptable amount by the responder:

$$
\text { Proposer pie-sharing strategy: } Z=\Phi E[Y \mid M] \text {. }
$$

Given that $E[Y \mid M] \leq Y$ and $\Phi<0.5$, it turns out that $Z<(Y-Z)$ : the proposer is not subject to adverse inequality. The utility of a proposer utility who receives $Y$ and plays his best pie-sharing is:

$$
\begin{aligned}
U(Y, Z, M) & =Y-Z-c|Y-M| \\
& =Y-\Phi E[Y \mid M]-c|Y-M|
\end{aligned}
$$

A proposer who aims to maximize his utility must decide on the message $M$ that he sends to the responder, depending on his endowment $Y$ and his type (honest or liar). A honest proposer will always declare the true amount $(M=Y)$ and a liar will declare a false amount $(M \neq Y)$. We admit that the optimal false message can be written as a (lying) function in $Y$, denoted by $g(Y)$ :

$$
\text { Proposers' communication strategy: }\left\{\begin{array}{ll}
M=Y & \text { if proposer is H-type } \\
M=g(Y) & \text { if proposer is L-type }
\end{array}\right. \text {. }
$$

The lying function presents the following properties:

$-g(0)=0:$ if the endowment is zero, the message can be only zero (the proposer has no choice but to tell the truth); 
- for $Y>0, g(Y)<Y$ : since the message aims to push down the expected value of $Y$, and lies are costly, the proposer has no incentive to declare an endowment higher than the actual one; ${ }^{8}$

- $g$ admits a reciprocal function $g^{-1}$ on the interval $[0, A]$.

\subsection{Equilibrium}

Let us denote by $f(M \mid L)$ (respectively $f(M \mid H)$ ) the conditional distribution of the signal $M$ given that the proposer is a liar (and respectively a honest person). By application of Bayes' theorem for continuous distribution functions, the probability for the responder to be matched with a L-type proposer who issues a message $M$ is:

$$
\operatorname{Pr}[L \mid M]=\frac{f(M \mid L) \operatorname{Pr}[L]}{f(M \mid L) \operatorname{Pr}[L]+f(M \mid H) \operatorname{Pr}[H]}
$$

In equilibrium, the responder should know the lying function $g(M)$; he can infer from the message $M$ the conditional expectation of $Y$. If $M$ exceeds $g(A)$, this signal can only be true (it was sent by a H-type proposer). In the opposite case, if $M \leq g(A)$, the expected value of $Y$ given $M$ is :

$$
\begin{aligned}
E[Y \mid M] & =\operatorname{Pr}[L \mid M] g^{-1}(M)+\{1-\operatorname{Pr}[L \mid M]\} M \\
& =\frac{f(M \mid L) \operatorname{Pr}[L] g^{-1}(M)+f(M \mid H) \operatorname{Pr}[H] M}{f(M \mid L) \operatorname{Pr}[L]+f(M \mid H) \operatorname{Pr}[H]} .
\end{aligned}
$$

an expression that acknowledges that $M$ can be sent either by a honest player (then $Y=M$ ), or by a liar (then $Y=g^{-1}(M)$ ). Furthermore, in equilibrium a responder can infer from the message of a liar the true value of $Y$, hence in the former expression we can substitute $g^{-1}(M)$ by $Y$. Moreover, as $Y \rightsquigarrow U(0, A)$, it turns out that $f(M \mid H)=1 / A$ and $f(M \mid L)=$

8 A quick look to the Bayesian revision of expectations (Eq. 10) shows that an overestimated message $(M>Y)$ pushes up the expected income, thus rises the value of the minimum acceptable offer. 
$\left|g^{-1 \prime}(M)\right| / A$. As $\operatorname{Pr}[H]=\alpha$, we get the final expression for the expected $Y$ given $M$ :

$$
E[Y \mid M]=\frac{\left|g^{-1 \prime}(M)\right|(1-\alpha) Y+\alpha M}{\left|g^{-1 \prime}(M)\right|(1-\alpha)+\alpha}
$$

Thus the utility of the L-type proposer (Eq. 6) can be written as:

$$
U(Y, Z, M)=Y-\Phi \frac{\left|g^{-1 \prime}(M)\right|(1-\alpha) Y+\alpha M}{\left|g^{-1 \prime}(M)\right|(1-\alpha)+\alpha}-c(Y-M) .
$$

The optimal announcement strategy for a L-type proposer is to choose the message $M$ that maximizes utility $U(Y, Z, M)$.

This problem probably presents several equilibria, depending on responders' beliefs. In this paper we limit the analysis to the simplest (and also intuitively appealing) case where responders present linear beliefs:

$$
\text { Responders' beliefs: } g(Y)=\mu Y \text {, with } \mu \in[0,1] \text {. }
$$

Then $g^{-1 \prime}(M)=1 / \mu$ and proposer's utility becomes:

$$
\begin{aligned}
U(Y, Z, M) & =Y-\Phi \frac{\frac{Y}{\mu}(1-\alpha)+\alpha M}{\frac{1}{\mu}(1-\alpha)+\alpha}-c(Y-M) \\
& =Y-\Phi \frac{\frac{Y^{2}}{M}(1-\alpha)+\alpha M}{\frac{Y}{M}(1-\alpha)+\alpha}-c(Y-M) \\
& =Y-\Phi \frac{(1-\alpha) Y+\alpha \frac{M^{2}}{Y}}{(1-\alpha)+\alpha \frac{M}{Y}}-c(Y-M) .
\end{aligned}
$$

The first order optimality condition:

$$
\frac{\partial U}{\partial M}=-\Phi \frac{\left[(1-\alpha)+\alpha \frac{M}{Y}\right] 2 \alpha \frac{M}{Y}-\frac{\alpha}{Y}\left[(1-\alpha) Y+\alpha \frac{M^{2}}{Y}\right]}{\left[(1-\alpha)+\alpha \frac{M}{Y}\right]^{2}}+c=0
$$

leads to the optimal value, $M .^{9} \quad$ The latter is a linear function of the endowment $Y$, consistent with responders' beliefs:

$$
M=\frac{1}{\alpha}\left\{\left[\frac{(1-\alpha)}{\left(1-\frac{c}{\Phi}\right)}\right]^{1 / 2}-(1-\alpha)\right\} Y .
$$

\footnotetext{
${ }^{9}$ Wa can check that $\partial^{2} U / \partial M^{2}<0, \forall M$.
} 
Notice that, in equilibrium there is a single value of $\mu$ consistent with responders' beliefs, defined by:

$$
\mu=\frac{1}{\alpha}\left\{\left[\frac{\Phi(1-\alpha)}{\Phi-c}\right]^{1 / 2}-(1-\alpha)\right\} .
$$

This value exists iif $c<\Phi$ (existence condition). We can remark that $\mu=M / Y$ is increasing with $c$ : the smaller the marginal lying cost and the higher the size of the lie.

Furthermore, the equilibrium requires: $0<\mu<1$ :

$$
\begin{aligned}
& \mu>0 \Longleftrightarrow \frac{\Phi}{\Phi-c}>(1-\alpha) \text { is always true } \\
& \mu<1 \Longleftrightarrow c<\alpha \Phi
\end{aligned}
$$

If this last condition is verified, the existence condition $(c<\Phi)$ is also fulfilled; thus the necessary and sufficient condition for this equilibrium to exist is:

$$
N S C: c<\tilde{c}=\alpha \Phi .
$$

The equilibrium with lies requires that the $(1-\alpha)$ liars present a marginal cost of lying below the critical value $\tilde{c}$. Notice that the solution also holds in the special case where liars present no lying aversion $(c=0)$. Individuals with a marginal lying cost above $\tilde{c}$ actually belong to the group of H-type proposers; such a person has no incentive to deviate from the truth-telling strategy, since the cost of lying would exceed its benefit from making a lower offer.

We recall that in this theoretical model agents differ only with respect to the (marginal) lying cost. We have shown that if there are at least some honest persons and for all the others lying costs are small enough $(c<\tilde{c})$, in equilibrium the latter will systematically understate $Y$, i.e. they declare $M<Y$. Responders adjust their beliefs in keeping with the message; in equilibrium they accept all offers. ${ }^{10}$ Thus, compared with a no-lie (or a perfect information)

\footnotetext{
${ }^{10}$ In real interactions, responders might have a different aversion to inequality, unknown to the proposer. If the latter makes his offer according to his expected aversion to inequality of responders, then some offers can be rejected.
} 
environment, honest proposers who get $Y<g(A)$ are worse-off since they must make higher offers, while liars are better-off, since they can make lower offers.

\section{The Experiment}

\subsection{Experimental Design}

In this section, we report on an experiment where we asked flesh and blood subjects to play an ultimatum game combined with a message game. The only difference with the theoretical model is that we set now a positive lower bound on the amount that can be provided by the computer. The main steps are listed below (see Appendix for instructions):

Step 1. Proposer gets $Y$ experimental currency units. The endowment $Y$ is picked by the computer with even chances among integers in the interval $[50 ; 100]$.

Step 2. He sends a message $M$ to the responder, informing him about the amount $Y$, with $M \in[50 ; 100]$. If $M=Y$, he tells the truth, if $M \neq Y$, he lies.

Step 3. He makes an offer $Z$ (with $Z \in[0 ; Y]$ ).

Step 4. Responder gets the message $M$ and the offer $Z$. He must decide whether to accept or reject the offer. If he accepts, the amounts are due; if else, both players get nothing.

The whole procedure was common knowledge. We run three sessions. The first was performed at the Behavioral Research Lab of ESSEC Business School on February 6, 2012, with a total of 26 participants; two other sessions were performed at the ESC Dijon Experimental Lab (LESSAC), on February 21, 2012, with 18 participants and on February 23, 2012, with 30 participants. Subjects were recruited from the student population of the schools, who answered to a call for paid decision experiments. The experimental design was presented via computer interface and all interactions were computerized. The program was written in z-Tree (Fischbacher, 2007). Each subject was assigned at random with a PC terminal. We make sure that no subject has participated more than once in this experiment. A short 
introductory questionnaire allows to make sure that students understand well the problem.

The roles (proposer/responder) were assigned one for all at the outset of the game, but players were not informed of their role before each round started. Each proposer played the game four times against changing anonymous partners (Mitzkewitz and Nagel, 1993); we gathered a total of 148 observations (37 independent per round).

We randomly chose one of the four rounds to be paid for real money, at an exchange rate of 10 euro for 100 experimental currency units. ${ }^{11}$ The test has lasted for 18 minutes on average, and players earned 4.80 euros (including a 2 euro fixed participation amount). ${ }^{12}$

\subsection{Results: Proposer behavior}

Lying by understating the actual endowment $Y$ appears to be the systematic behavior. Proposers adopted this strategy in $88.5 \%$ of the overall 148 decisions. They told the truth in $8.8 \%$ of the cases, and the number did not vary much from one round to another. Subjects overstated the actual endowment in a very small number of cases $(2.7 \%)$; this strategy does not fit well in our theoretical framework. Some misunderstanding of the problem might explain them, an assumption that seems to be vindicated by the declining number over the four rounds (from to 2 to 0 ). Table 1 indicates the distribution of messages per round, depending on their nature.

\begin{tabular}{|l|l|l|l|l|l|}
\hline & Round 1 & Round 2 & Round 3 & Round 4 & All rounds \\
\hline Total observations & 37 & 37 & 37 & 37 & 148 \\
\hline Truth telling $(M=Y)$ & 3 & 5 & 2 & 3 & 13 \\
\hline Strategic lies $(M<Y)$ & 32 & 31 & 34 & 34 & 131 \\
\hline Irrational lies $(M>Y)$ & 2 & 1 & 1 & 0 & 4 \\
\hline
\end{tabular}

Table 1. The distribution of proposer messages

\footnotetext{
11 See Laury (2005) for the validity of this approach.

12 Total compensation was higher, since they participated in two other experiments of a different nature.
} 
Table 2 indicates the average endowment $(Y)$, the average declared endowment $(M)$ and the average offer $(Z)$ per round and over the four rounds.

\begin{tabular}{|l|l|l|l|l|l|}
\hline & Round 1 & Round 2 & Round 3 & Round 4 & All rounds \\
\hline Av. $Y$ & $74.70(14.19)$ & $78.30(12.53)$ & $71.84(14.08)$ & $74.19(16.19)$ & $74.76(14.35)$ \\
\hline Av. $M$ & $60.16(9.37)$ & $61.78(9.59)$ & $59.59(11.76)$ & $60.00(10.57)$ & $60.39(10.29)$ \\
\hline Av. $Z$ & $26.68(7.38)$ & $28.68(6.64)$ & $26.11(9.48)$ & $27.91(7.45)$ & $27.34(7.79)$ \\
\hline
\end{tabular}

Table 2. Average actual and declared endowment, average offer.

(Standard deviation between brackets)

Table 3 presents three interesting ratios (in percent), taking into account only the strategic lies (i.e., messages that understate the actual endowment, $M<Y$ ). The second line shows the average ratio between the claimed and the actual endowment: proposers tend to discount the actual endowment by $20.5 \% .{ }^{13}$ The third line is the average ratio between the offer and the actual endowment: on average offers represent $36 \%$ of the endowment, in line with other experiments surveyed by Oosterbeek et al. (2004). The fourth line shows that on average offers represent $45 \%$ of the claimed amount $(Z / M)$.

\begin{tabular}{|l|l|l|l|l|l|}
\hline & Round 1 & Round 2 & Round 3 & Round 4 & All rounds \\
\hline Nb. obs. & 32 & 31 & 34 & 34 & 131 \\
\hline Av. $M / Y$ & 78.86 & 75.79 & 81.74 & 81.16 & 79.48 \\
\hline Av. $Z / Y$ & 34.71 & 35.69 & 37.60 & 36.89 & 36.26 \\
\hline Av. $Z / M$ & 44.24 & 47.52 & 45.75 & 45.69 & 45.78 \\
\hline
\end{tabular}

Table 3. Understated endowment: Average values of three important ratios

(in percent)

\footnotetext{
${ }^{13}$ If we consider all the messages (including true ones and overstatements), the average discount is $17.64 \%$.
} 
An examination of the data change from one round to another suggests that the learning effect is limited, if any. Except the decline in the almost very small number of "irrational lies" (Table 1), there is no clear trend in the absolute or relative data. More intuition about the data is brought by Figure 1. This figure shows the pairs of actual $(Y)$ and declared $(M)$ endowment, for all subjects, as well as the regression lines (one for each round). The symbol is specific to the round (there are thus four symbols). While several dots are located on the $45^{\circ}$ line (sometimes proposers tell the truth), the huge majority of dots lay below the line, illustrating the dominant underestimating strategy. The large dispersion of dots would suggest that individuals are heterogenous with respect to lying aversion.

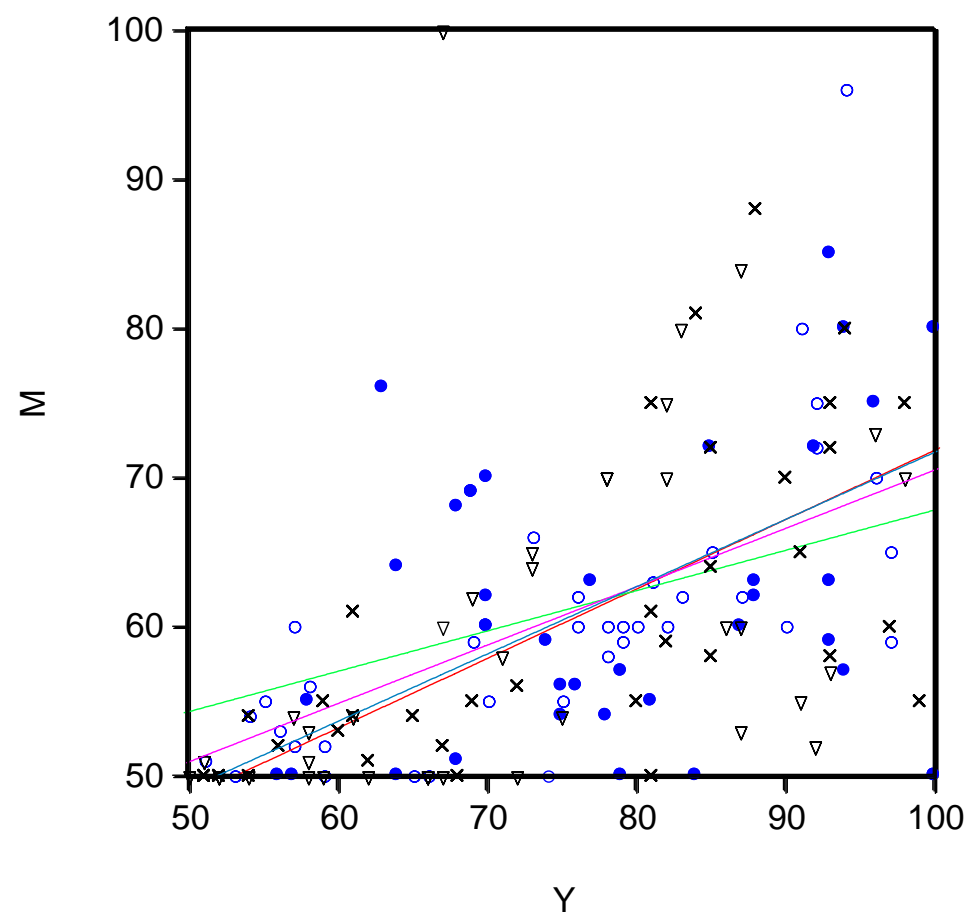

Figure 1: Actual and declared endowment

If responders fully trust proposers, then the half-declared endowment would correspond to the "fairest" equal split of the amount. Figure 2 is a scatter diagram between offers $Z$ (on 
the vertical axis) and half of the message, $0.5 M$. The majority of observations are located either on or below the $45^{\circ}$ line.

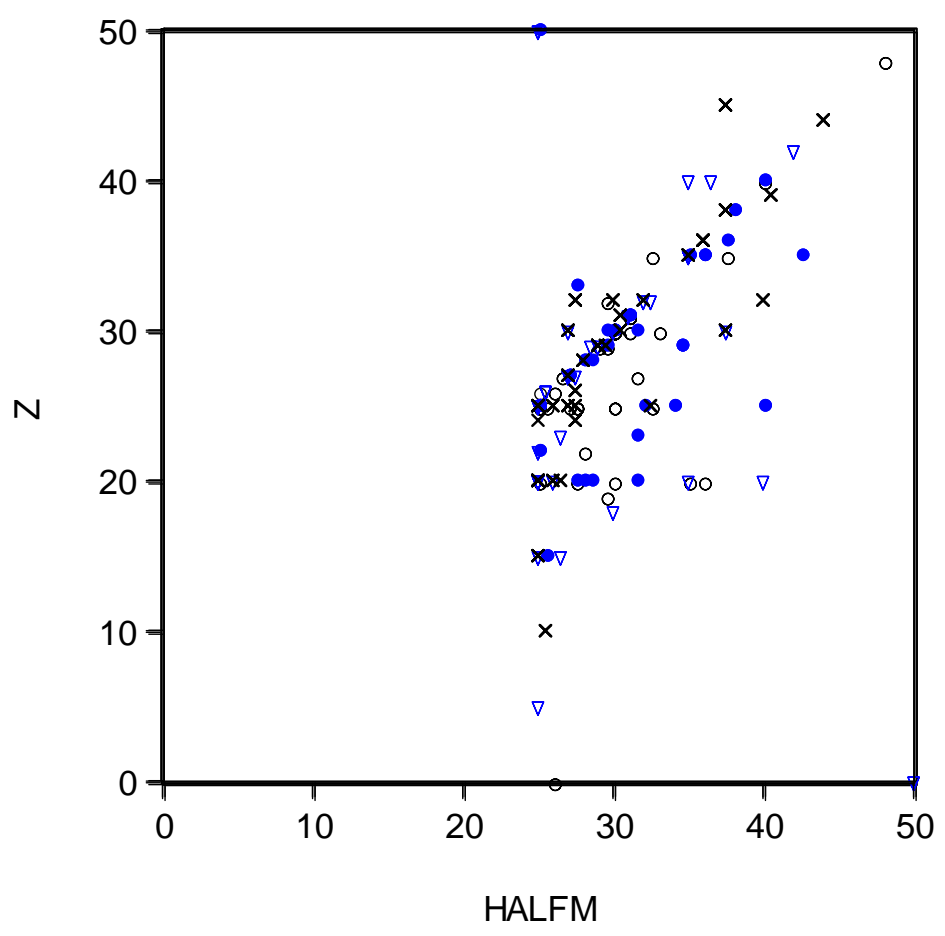

Figure 2: Half-declared endowment and offer

More insights about the proposer's behavior can be obtained from a panel data regression analysis. We keep the notation $Z$ for the offer, $Y$ for the endowment and define $L I E=Y-M$, as the difference between the actual and the declared endowment. The basic "proposer equation" takes the form:

$$
Z_{i t}=c+\theta_{t}+a Y_{i t}+b L I E_{i t}+u_{i}+\epsilon_{i t}
$$

where $i$ indexes the player, with $i \in[1,37]$, and $t$ indexes the round, with $t \in\{1,2,3,4\}$. Parameter $a$ captures the relationship between offers and endowment when controlling for the lie, the parameter $b$ indicates the variation in the offer for a one-dollar lie. Denoting the common constant by $c$, the parameter $\theta_{t}$ denotes a round-specific intercept and would 
capture any group learning effect over the rounds; to avoid colinearity, one round must be dropped (we choose the first one as the benchmark). The individual specific effect $u_{i}$ captures individual unobserved heterogeneity, and $\epsilon_{i t}$ is an indiosyncratic error. In a fixed effect (FE) specification $u_{i}$ are treated as constants over time, in a random effect (RE) model the $u_{i}$ are treated as random variables rather than fixed constants (furthermore, in the RE approach, $u_{i}$ and $\epsilon_{i t}$ are assumed to be independent). It is difficult to say which of the two methods fits best to our model; the RE specification is appealing since the individuals in our test are a small sample of a much larger population (of student subjects), the FE is interesting, since it is not clear why individual effects should be uncorrelated with the other regressors. We therefore provide in Table 4 an estimate of Eq. (22) using both methods.

\begin{tabular}{|l|l|l|}
\hline & $\mathrm{FE}$ & $\mathrm{RE}$ \\
\hline$Y$ & $0.317^{* * *}$ & $0.334^{* * *}$ \\
\hline$L I E$ & $-0.140^{* *}$ & $-0.188^{* * *}$ \\
\hline$c$ & $5.029^{n s}$ & $4.407^{n s}$ \\
\hline$\theta_{2}$ & $1.137^{n s}$ & $1.168^{n s}$ \\
\hline$\theta_{3}$ & $0.017^{n s}$ & $0.041^{n s}$ \\
\hline$\theta_{4}$ & $1.356^{n s}$ & $1.348^{n s}$ \\
\hline $\mathrm{Nb}$. obs & 148 & 148 \\
\hline$R^{2}-$ overall & 0.22 & 0.22 \\
\hline$\sigma_{u}$ & 4.91 & 3.84 \\
\hline$\rho$ & 0.42 & 0.31 \\
\hline Proba all $u_{i}=0$ & 0.00 & - \\
\hline
\end{tabular}

Table 4. Proposer offer equation: Estimation output.

(*** stands for significant at $1 \%,{ }^{* *}$ stands for significant at $5 \%, n s$ for non significant) 
The two models (FE and RE) provide similar qualitative results. A Hausman test confirms that individual disturbance terms $u_{i}$ are uncorrelated with the regressors (Chi2 $(5)=3.18$; p-value $=0.6726)$, which recommends the RE method. ${ }^{14}$

The estimated coefficients indicate that, all things equal, for every additional dollar in endowment, proposers increase their offer by 33 cents; a one-dollar lie would contribute to reduce the offer by 19 cents.

These findings are consistent with the theoretical model, according to which L-type proposers (i.e., those characterized by a relatively small marginal lying cost) would declare a smaller than actual endowment, just in order to prompt responders to reduce the expected endowment (of proposers) and make lower offers. Our results also match those put forward by Croson et al. (2003) who showed that in presence of imperfect information and lies, for every additional dollar endowment, proposers raise their offer by 39 cents. They also report that a lie (as measured by a dummy variable) would reduce the offer by 1.5 dollars. ${ }^{15}$

Round specific effects are not statistically significant, suggesting that over a small number of repeated interactions the proposers' learning effect is limited.

\subsection{Results: Responder behavior}

Table 5 indicates the basic statistics pertaining to the responder's decision. On average, the rejection rate at $24 \%$ is slightly higher than usual, but not excessive (Oosterbeek et al. 2004 refer to a rejection rate of $16 \%$ on average).

Over the total of 148 observations, the average amount of the accepted offers (29.04) is higher than the average amount of the rejected offers (21.88). A Mann-Whitney U-test for

\footnotetext{
14 The Breusch-Pagan Lagrange multiplier test suggests that the RE specification is to be preferred to a simple OLS regression.

${ }^{15}$ In a companion paper (Besancenot, Dubart and Vranceanu, 2012), we study a power-to-take (or demand ultimatum) game coupled with a similar message game and found that the message senders (responders in that game) also lie strategically: when they lie, they make less advantageous offers.
} 
independent observations shows that the difference between the average of accepted offers and the average of rejected offers is significant at $5 \%$ in rounds 1, 3 and 4 (it is not significant in round 2).

The same test shows that the average declared endowment (Av. M) in rejected offers is not statistically different from the average declared endowment in accepted offers in any of the four rounds.

\begin{tabular}{|c|c|c|c|c|c|}
\hline & Round 1 & Round 2 & Round 3 & Round 4 & All rounds \\
\hline Acceptance rate & 0.84 & 0.76 & 0.70 & 0.76 & 0.76 \\
\hline Av. $Z$, accepted offers & 28.32 & 29.61 & 28.96 & 29.32 & 29.04 \\
\hline Av. $Z$, rejected offers & 18.17 & 25.78 & 19.36 & 23.56 & 21.88 \\
\hline Av. $M$, accepted offers & 60.48 & 62.39 & 59.54 & 61.18 & 60.91 \\
\hline Av. $M$, rejected offers & 58.50 & 59.89 & 59.73 & 56.33 & 58.69 \\
\hline Av. $Z / Y$, accepted offers & 0.47 & 0.48 & 0.49 & 0.48 & 0.48 \\
\hline Av. $Z / Y$, rejected offers & 0.31 & 0.43 & 0.35 & 0.41 & 0.38 \\
\hline
\end{tabular}

Table 5. Basic statistics for the responder decision

We also perform a regression of the decision dummy $A R D$ (which takes the value 1 when the offer is accepted, 0 when rejected) on the offer $Z$ and the declared endowment $M$ :

$$
A R D_{j t}=c+\theta_{t}+q Z_{j t}+r M_{j t}+u_{j}+\epsilon_{j t}
$$

where the index $j$ corresponds to a Responder, and $t$ indexes the round. As in the former regression, $\theta_{t}$ denotes the round specific effect (to avoid colinearity we omit the first round), 
$u_{j}$ captures the individual heterogeneity and $\epsilon_{j t}$ is the idiosyncratic error. Given the binomial nature of $A R D$ we implement a probit and logit model, both of them with a random effect (RE) specification. The output is presented in Table 6, where, for each method, a first column provides the regression coefficients, and a second column indicates the related marginal effects. ${ }^{16}$

\begin{tabular}{|l|l|l|l|l|}
\hline \multicolumn{2}{|l|}{} & \multicolumn{2}{l|}{ Probit RE } & \multicolumn{2}{l|}{ Logit RE } \\
\hline & Coefficient & Marginal & Coefficient & Marginal \\
\hline$M$ & $-0.018^{n s}$ & -0.004 & $-0.03^{n s}$ & -0.004 \\
\hline$Z$ & $0.126^{* * *}$ & 0.030 & $0.217^{* * *}$ & 0.028 \\
\hline$\theta_{2}$ & $-0.675^{n s}$ & -0.188 & $-1.103^{n s}$ & 0.170 \\
\hline$\theta_{3}$ & $-0.572^{n s}$ & -0.157 & $-0.984^{n s}$ & 0.149 \\
\hline$\theta_{4}$ & $-0.640^{n s}$ & -0.177 & $-1.070^{n s}$ & 0.165 \\
\hline Const & $-0.877^{n s}$ & - & $-1.611^{n s}$ & - \\
\hline Nb. obs. & 148 & & 148 & \\
\hline Log likelihood & -65.30 & & -65.45 & \\
\hline$\sigma_{u}$ & 0.64 & & 1.09 & \\
\hline$\rho$ & 0.29 & & 0.27 & \\
\hline
\end{tabular}

Table 6. Responder accept/reject decision equation: Estimation output

(*** stands for significant at less than $1 \%$, ns for non significant)

Like in the Proposer equation, round specific effects are not statistically significant. Results here too are consistent with findings by Croson et al. (2003): while the offer $Z$ has a statistically significant impact on the probability to accept an offer, the message $M$ has not. The estimate of the marginal effects shows that around the average offer, chances to have an

\footnotetext{
${ }^{16}$ A FE logit model provides similar qualitative results.
} 
offer accepted increase by 3 percentage points for one-dollar increase in the offer $Z$.

In order to bring some additional intuition to these results, let us perform some rule-ofthumb calculations. We know that on average a six dollar lie reduces proposers' offer by one dollar (Table 4), but this rises the probability of having the offer rejected by responders by 3 percentage points (Table 5). We consider now a L-type proposer with a zero marginal cost of lying. Let us assume that he gets 75 dollars (the expected value of the uniform distribution over $[50,100])$, tells the truth and makes an offer $Z=0.33 * 75=25 .{ }^{17} \quad$ Given the average rejection rate, his expected payoff is $(75-25) * 0.76=38$. Now, if he tells a six dollar lie, he will reduce his offer by one dollar, from 25 to 24 dollars. For sure, if the probability of having the offer accepted does not vary, he would make a profit. But since for a smaller offer the probability to have it accepted declines by 3 percentage points, the expected gain will be $(75-24) * 0.73=37.23$. It turns out that in the neiborghood of these average values, a onedollar lie brings about an ex post dollar loss to the "unethical" proposer (without counting any would-be lying cost on top of it). These numbers suggest that in this game proposers are subject to a form of overconfidence bias: they tend to believe that responders will take for granted their message, but this does not happen.

\section{Conclusion}

In this paper, we studied an ultimatum game with uninformed responders and proposers who can communicate strategically about their endowment, knowing that the responders will not be able to verify their claim. The theoretical analysis presented in the first section suggests that while there are at least some honest people in this world, it is worth lying for the others. More precisely, proposers willing to lie can be expected to understate the actual endowment

\footnotetext{
${ }^{17}$ Here 0.33 is the average share offered by a honest person according to the estimated offer equation (Table $4)$.
} 
and make lower offers.

The empirical findings corroborate the predictions of the theoretical model as far as the proposers are concerned. In $88.5 \%$ of the messages, proposers discount their endowment by $20.5 \%$ on average. These lies are systematically associated with lower offers; for every one-dollar lie, proposers reduce their offer by 19 cents. However, the experiment challenges the theoretical analysis as far as responders' are concerned since they do not react as the proposers expect: the endowments declared by proposers have little impact on their decision whether to accept/reject the offer. They behave as if the received message is genuine "cheap talk". Only the amount of the offer itself matters in their decision whether to accept/reject it: a one-dollar reduction in the offer reduces the acceptance rate by 3 percentage points.

If proposers reduce their offers because they "believe in their own lies", but responders are skeptical, the final outcome is a net welfare loss, since the frequency of rejected offers (bringing zero gains for both players) will be higher than in a lie-free environment. In this simple experiment, attempts to manipulate through lying are detrimental not only to those who receive the wrong message, but also to those who deliver it. Despite this, the people in a position to $\div$ lie do lie; they are probably victims of a self-confidence bias concerning their ability to cheat.

It is difficult to extend the insights from this simple game to any other form of selfish lies. However, if further research can show that lying systematically brings about a socially inefficient outcome, then the emergence of a social norm banning lying would appear as a natural outcome.

\section{References}

Anton, Ronald J., 1990, Drawing the line: An exploratory test of ethical behavior in negotiations, Journal of Conflict Management, 1, pp. 265-280 
Bearden, Neil, J., 2001, Ultimatum bargaining experiments: The state of the art, Available at $S S R N$ : http://ssrn.com/abstract $=626183$.

Besancenot, Damien, Delphine Dubart and Radu Vranceanu, 2012, The value of lies in a power-to-take game with imperfect information, Working Paper ESSEC 1205, ESSEC Business School.

Boles, Terry, L., Rachel T. A. Croson and J. Keith Murnighan, 2000, Deception and retribution in repeated ultimatum bargaining, Organizational Behavior and Human Decision Processes, 83, 2, pp. 235-259.

Camerer, Colin, 2003, Behavioral Game Theory. Experiments in Social Interaction, Princeton University Press, Princeton

Charness, Gary and Martin Dufwenberg, 2010, Bare promises: An experiment, Economics Letters, 107, pp. 281-283.

Charness, Gary and Martin Dufwenberg, 2006, Promises and partnership, Econometrica, 74, pp. 1579-1601.

Chen, Ying, Navin Kartick and Joel Sobel, 2008, Selecting cheap talk equilibria, Econometrica, 76, 1, pp. 117-136

Crawford, Vincent and Joel Sobel, 1982, Strategic information transmission, Econometrica, 50, pp. 1413-1451.

Croson, Rachel T. A., 1996, Information in ultimatum games: An experimental study, Journal of Economic Behavior and Organization, 30, pp. 197-212.

Croson, Rachel T. A., Terry L. Boles, J. Keith Murnighan, 2003, Cheap talk in bargaining experiments: Lying and threats in ultimatum games, Journal of Economic Behavior and Organization, 51, pp. 143-159.

Erat, Sanjiv and Uri Gneezy, 2011, White lies, Forthcoming, Management Science.

Fehr, Ernst and Klaus M. Schmidt, 1999, A theory of fairness, competition, and cooperation, Quarterly Journal of Economics, 114, 3, pp. 817-868.

Fischbacher, Urs, 2007, z-Tree: Zurich toolbox for ready-made economic experiments, Experimental Economics, 10, pp. 171-178.

Gneezy, Uri, 2005, Deception: The role of consequences, American Economic Review, 95, 1, pp. 384-394.

Güth, Werner, Rolf Schmittberger and Bernd Schwartze, 1982, An experimental analysis of the ultimatum bargaining, Journal of Economic Behavior and Organization, 3, pp. $367-388$.

Güth, Werner, Steffen Huck, Peter Ockenfels, 1996, Two-level ultimatum game with incomplete information: An experimental study, Economic Journal, 106, 436, pp. 593604 .

Hao, Li and Daniel Houser, 2010, Honest lies, GMU Working Paper in Economics, No. 11-16. Available at SSRN: http://ssrn.com/abstract=1801546. 
Hurkens, Sjaak and Navin Kartik, 2009, Would I lie to you? On social preferences and lying aversion, Experimental Economics, 12, pp. 180-192.

Kagel, John H., Kim Chung, Moser Donald,1996, Fairness in ultimatum games with asymmetric information and asymmetric payoffs, Games and Economic Behavior, 13, pp. $100-110$.

Kartik, Navin, 2009, Strategic communication with lying costs, Review of Economic Studies, 76, 4, pp. 1359-1395.

Kartik, Navin, Marco Ottaviani and Francesco Squittani, 2007, Credulity, lies, and costly talk, Journal of Economic Theory, 134, pp. 93-116.

Laury, Susan, K. 2005, Pay one of pay all. Random selection of one choice for payment, Andrew School of Political Science, Working Paper 0613.

Lewicki, Roy J., 1983, Lying and deception: A behavioral model, In: M. Bazerman an R. Lewicki, eds., Negotiation in Organizations, Sage, Beverly Hills, CA.

Lewicki, Roy J. and Neil Stark, 1996, What is ethically appropriate in negotiations: An empirical examination of bargaining tactics, Social Justice Research, 9, 1, pp.69-95.

Lundquist, Tobias, Tore Ellingsen and Magnus Johannesson, 2009, The aversion to lying, Journal of Economic Behavior and Organization, 70, 1-2, pp. 81-92.

Mitzkewitz, Michael and Rosemarie Nagel, 1993, Experimental results on ultimatum games with imperfect information, 1993, International Journal of Game Theory, 22, pp. 171-198.

Oosterbeek, Hessel, Randolph Sloof and Gijs van de Kuilen, 2004, Cultural differences in ultimatum game experiments: Evidence from a meta-analysis, Experimental Economics, 7, pp. 171-188.

Rapoport Amnon and Sundali, James A, 1996, Ultimatums in two-persons bargaining with one-sided uncertainity: Offer games, International Journal of Game Theory, 25, pp. $475-348$.

Sánchez-Pagés, Santiago, 2006, An experimental study of truth-telling in a senderreceiver game, Games and Economic Behavior, 67, 1, 67-112.

Shapiro, Debra L. and Robert J. Bies, 1994, Threats, bluffs, and disclaimers in negotiations, Organization, Behavior and Human Decision Processes, 60, pp. 14-35.

Sobel, Joel, 1985, A theory of credibility, Review of Economic Studies, 52, 4, pp. 557573 .

Straub, Paul G and J. Keith Murnighan, 1995, An experimental investigation of ultimatum games: Information, fairness, expectations, and lowest acceptable offers, Journal of Economic Behavior and Organization, 27, pp. 345-364.

Vanberg, Christoph, 2008, Why do people keep their promises? An experimental test of two explanations, Econometrica, 76, 6, pp. 1467-1480. 


\section{Annex. Instructions}

\section{Screen 1. General information}

Good Morning,

Thank you for participating to this study.

It presents an interaction between two individuals on how to share a sum of money, denominated in ECU (for Experimental Currency Units)

Individuals play in pairs, under complete anonymicity, behind the computer screen. Pairs are rematched at every round. You never play twice with the same player. Identities of the persons will never be revealed.

At the beginning of the game, one of the two players gets an endowment. He must then make an offer to the other on how to divide this amount between them. For instance, if he receives 100 ecus, he can make an offer 10, that is a division 90:10. Then the other player can either accept this offer or reject it. If accepted, the first player who made the offer keeps the 90 ecus and the second player who accepted the offer keeps the 10 ecus; if rejected, both players get nothing. Thus by giving up his own gain, the second player can inflict a loss to the former.

In this game, the player who receive the offer (Player 2), will never learn the exact amount received by the first player (Player1). He only knows that the amount is chosen by the computer, with equal chances, among the integers in the set $[50,100]$.

Before making his offer, Player 1 must sent a message to Player 2, indicating the amount he got at that round. Player 2 cannot verify this information (and Player 1 knows this).

\section{Screen 2. Some clarification questions}

These questions aim at helping you to better understand the rule of the game, by means of some fictitious examples. 
1. You are the person who receives the offer (your are therefore Player 2).

Assuming that you know that Player 1 got 100 ecus, if he offer you 25 ecu (75:25), would you accept this offer ? (Yes/No)

Assuming that you know that Player 1 got 50 ecus, if he offer you 25 ecu (25:25), would you accept this offer ? (Yes/No)

2. You are the person who makes the offer (you are therefore Player 1)

Assuming that you receive 90 ecus, but Player 2 only knows that you get a sum in the interval $[50,100]$,

- What amount would you claim to have obtained ? [...]

- How much money would you offer him ? [...]

\section{Screen 3. The rule of the game}

Step 0: At the beginning of the game, Player 1 receives an amount $Y$ draw at random by the computer in the interval $[50,100]$. Every integer has equal chances to be chosen. Player 2 will never learn this amount, but knows that it is draw from the interval $[50,100]$ with equal chances.

Step 1. Player 1 offers to Player 2 an amount $Z$ between 0 and $Y$. He also sends a message to Player 2, where he makes a statement about his endowment $Y$.

Step 3. Player 2 learns the offer $Z$ and the message about $Y$, and decides whether to accept/reject this offer. If he accepts, he gets $Z$ and Player 1 gets $Y-Z$, if he rejects this offer, both players get nothing. Player 2 will not be able to verify the information about the actual amount received by Player 1 .

You will play this game four times in a row. One round chosen at random will be remunerated in cash, at the exchange rate $100 \mathrm{ECU}=10$ euros.

\section{Screen 4a. The decision}


You are Player 1.

Following a random draw by the computer in the interval $[50,100]$, you get the amount $[Y]$.

You must make an offer $Z$ to Player 2, in the interval $[0, Y]$.

You will also send him a message about the money you got. Player 2 will not be able to verify your claim.

If at the next stage, Player 2 accepts the offer, you will gain $(Y-Z)$ and he gains $Z$. If he rejects your offer, both of you will get zero.

Attention please. Actual decision. For this round, the computer provides you with [...] ecu. What amount do you declare to Player 2? [...] What offer do you submit to Player 2? $[\ldots]$

\section{Screen $4 \mathrm{~b}$. The decision}

You are Player 2.

At the previous stage, Player 1 got an amount in the interval [...].

He informs you that he got $[. .$.$] ecus$

He makes you an offer of $[\ldots]$ ecus

You must decide whether to accept or not this offer. If you reject this offer, gains of both of you are zero.

Make your decision now: [Accept] - [Reject $]$

\section{Screen 5a. Results}

Results. You are Player 2. Player 1 proposed [Z]. You accepted / rejected his offer. Your gain for this round is $[\mathrm{Z}] / 0$.

\section{Screen 5b. Results}

Results. You are Player 1. You proposed [Z]. Player 2 accepted / rejected your offer. 
Your gain for this round is $[\mathrm{Y}-\mathrm{Z}] / 0$. 
ESSEC Business School Avenue Bernard Hirsch BP 50105

95021 Cergy-Pontoise Cedex France

Tél. +33(0)134433000

$\mathrm{Fax}+33(0) 134433001$

www.essec.fr

\section{ESSEC Executive Education}

CNIT BP 230

92053 Paris-La Défense

France

Tél. +33(0)146924900

Fax +33(0)1 46924990

http:l/formation.essec.fr

ESSEC Business School

Singapore Campus

100 Victoria Street

National Library Building \# 13-02

Singapore 188064

essecasia@essec.fr

Tél. +6568849780

Fax +6568849781

www.essec.edu

\section{Informations}

Alison Bougi

+33 (0)134433358

bougi@essec.edu

unw.essec.fr

research.center@essec.fr

ISSN 1291-9616 